\title{
VISIBILIDAD Y PAISAJE EN EL SECTOR CENTRO-ORIENTAL DE LA PROVINCIA DE CORRIENTES
}

\author{
Fernando W. P. Oliva ${ }^{1}$ y María Cecilia Panizza ${ }^{2}$ \\ Recibido: 18 de marzo de 2019. Aceptado: 20 de mayo de 2019
}

\begin{abstract}
Resumen
En este trabajo se propone el estudio de dos sitios específicos del sector centro-oriental de la Provincia de Corrientes, Itá Pucú y Tres Cerros, caracterizados por su ubicación a una elevada altura en el marco de un paisaje uniformemente llano. Se aplican las concepciones provistas por la arqueología del paisaje, principalmente aquellas relacionadas con la visibilidad, visibilización y control visual. A través de programas informáticos se testeó su visibilidad sobre el entorno circundante, mediante el cálculo de las cuencas visuales y el punto del observador. Se postula que los sitios abordados podrian haber funcionado como "hitos", como referentes espaciales para conseguir orientación en el paisaje, como indicadores de caminos y limites o fronteras entre grupos que habitaron este espacio en el pasado.
\end{abstract}

Palabras claves: monumentalidad, visibilidad, paisaje, Mesopotamia/Corrientes

\begin{abstract}
This paper proposes the study of two specific sites of the central-eastern sector of the province of Corrientes, Itá Pucú and Three Hills, characterized by its location at high altitudes within the framework of an evenly plain landscape. Apply the provided designs for the archaeology of the landscape, mainly those related to visibility, visibility and visual control. Run through computer programs tested its visibility on the surrounding environment, using calculating Visual basins and the point of the observer. Postulated that the studied sites could have functioned as "milestones", as relating space to get guidance in the landscape, as indicators of roads and boundaries, or boundaries between groups that inhabited this area in the past. Keywords: monumentality, visibility, landscape, Mesopotamia/Corrientes
\end{abstract}

1 Centro de Estudios Arqueológicos Regionales \& Departamento de Arqueología, Escuela de Antropología, Facultad de Humanidades y Artes, Universidad Nacional de Rosario. Entre Ríos 758, CP 2000. Rosario. E-mail: fwpoliva@gmail.com

2 CONICET, Centro de Estudios Arqueológicos Regionales, Facultad de Humanidades y Artes, Universidad Nacional de Rosario. Entre Ríos 758, CP 2000. Rosario. E-mail: mcpanizza@yahoo. com.ar 


\section{Introducción}

En el marco del Proyecto HUM 557 "Expresiones gráficas y arqueología monumental en el sector centro oriental de la provincia de Corrientes", acreditado en la Universidad Nacional de Rosario, se propone el estudio de dos sitios específicos, que se caracterizan por estar en una elevada altura dentro de un paisaje uniformemente 1lano. El primero es conocido como Itá Pucú, en la región del municipio de Mercedes, y el segundo es un conjunto denominado Tres Cerros, en el municipio de La Cruz (Figura 1). Los objetivos fueron determinar los indicadores de monumentalidad presentes en el registro arqueológico regional, valorarlos como lugares representativos dentro del área, contextualizándolos en el marco paisajístico en el cual se insertan; y por último, evaluar su estado de alteración/ deterioro en relación al turismo que reciben, a pesar de estar en campos privados. Considerando concepciones provistas por la arqueología del paisaje, principalmente aquellas relacionadas con la visibilidad, visibilización y control visual; se procedió a testear mediante programas informáticos su visibilidad sobre el entorno circundante, mediante el cálculo de las cuencas visuales y el punto del observador. La variabilidad temporal considerada abarca desde las sociedades cazadoras recolectoras hasta momentos de contacto hispano-indigena, con la instalación de misiones jesuíticas; con el fin de identificar cómo las diferentes sociedades se vincularon con su entorno natural y social en un proceso de construcción del paisaje cultural.

En el marco de la arqueología del paisaje, se propone que los sitios abordados en el presente trabajo podrian haber funcionado como "hitos", como referentes espaciales para conseguir orientación en el paisaje, como indicadores de caminos y limites o fronteras entre grupos. La utilización y artificialización del espacio natu- ral por parte de las sociedades cazadoras recolectoras primero, y sedentarias con sistemas de producción de alimentos después, puede ser lograda a través de monumentos generadores de un nuevo tipo de paisaje, y del control del tiempo obtenido por la visibilidad y permanencia de la acción social, expresada en registros inmuebles; en este sentido el espacio particular donde se emplaza se constituye en una huella de la construcción social del paisaje. Deben destacarse en este marco teórico, los conceptos de visibilidad, vinculado a la capacidad de ser visible desde fuera; y visibilización, relacionado a la capacidad de proporcionar visión desde adentro hacia afuera. Las propiedades visuales de una localización, como la amplia visibilidad del entorno, como es el caso de Itá Pucú, pueden ser importantes factores en la elección de un emplazamiento. En este sentido, el concepto de control visual de un espacio puede aportar elementos para discutir la hipótesis que postula a los sitios vinculados al manejo y control territorial del nacimiento de las cuencas hídricas con los sitios localizados en puntos estratégicos con amplia visibilidad.

\section{Área de estudio}

La provincia de Corrientes ocupa el centro geográfico de la cuenca del Plata en el noreste de Argentina ocupando una superficie de $88.000 \mathrm{~km}^{2}$ aproximadamente. Limita al norte con Paraguay y la provincia de Misiones, al oeste con las provincias de Chaco y Santa Fe, al sur con Entre Ríos y al este con Uruguay y Brasil. Está rodeada por el río Paraná, que determina su límite norte y por el río Uruguay, que marca su límite este. El paisaje en general es llano, por sectores con ondulaciones o lomadas, siendo característica la presencia de grandes superficies anegadas o anegables como lagunas y esteros que ocupan en conjunto, 


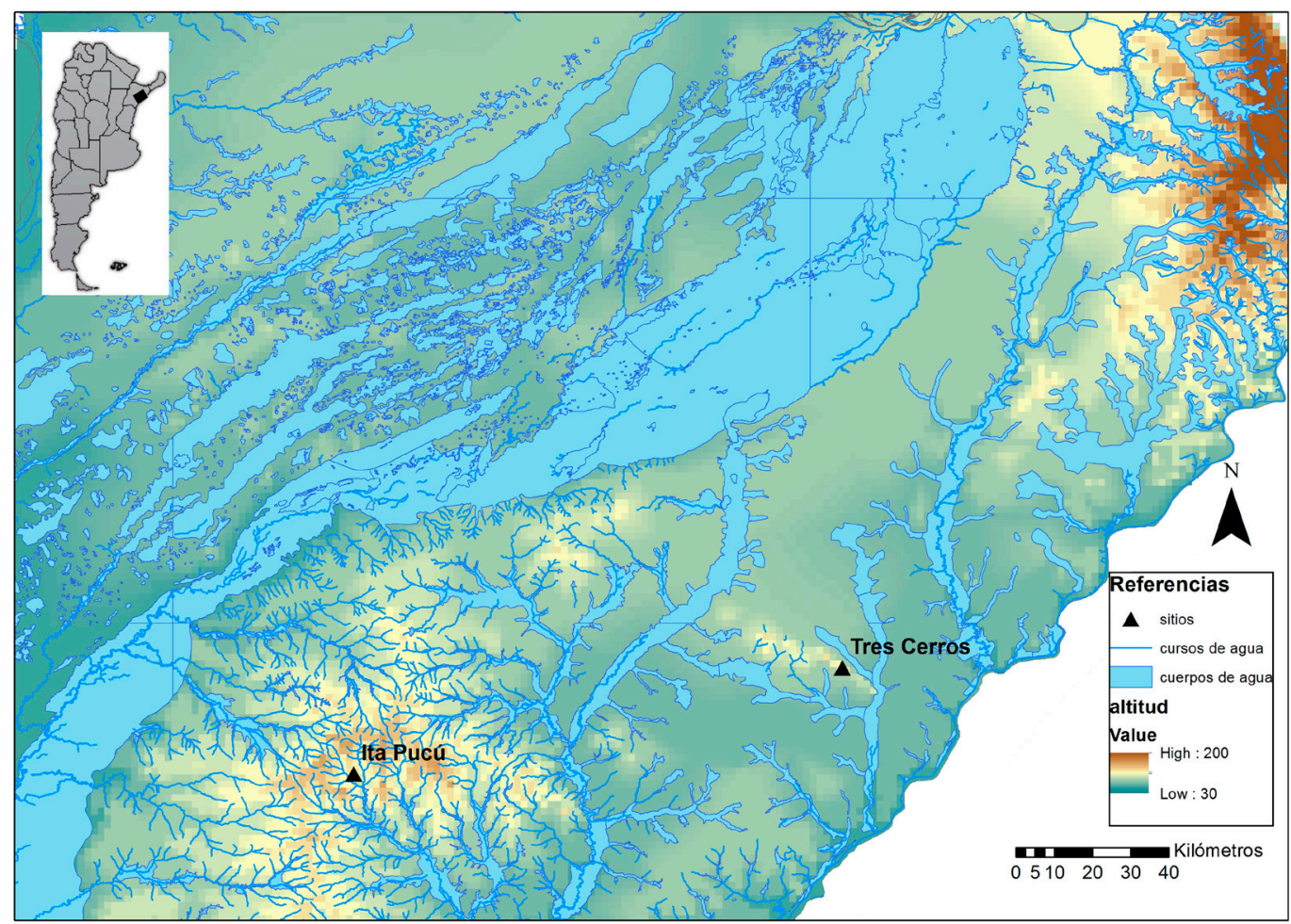

Figura 1. Ubicación fisica de los sitios analizados.

alrededor de $20.000 \mathrm{~km}^{2}$ y que se encuentran distribuidas en su mayor parte en la mitad occidental de la provincia, dentro de los cuales se halla uno de los humedales más importantes de Sudamérica, el Sistema Iberá (Escobar 1982). Es como una isla dentro de la Mesopotamia; al norte y oeste se encuentra limitada con el Río Paraná y al este con el Río Uruguay; al sur con los Ríos Mocoretá y Guarquiraró y un sector de frontera seca que la separan de la provincia de Entre Ríos, y al noreste los arroyos Itaembé y Chimiray y una breve extensión de frontera seca la delimitan de la provincia de Misiones (Acosta et al. 2009; Herbst y Santa Cruz 1999).

El clima correntino está caracteriza- do por un régimen térmico subtropical o templado cálido (Carnevali 1994), con temperaturas medias anuales que varian de norte a sur entre los $21.5 \mathrm{C}^{\circ}$ y $19 \mathrm{C}^{\circ}$, siendo enero el mes más cálido (media anual $27 \mathrm{C}^{\circ}$ ) y julio el más frío (media anual 14 $\mathrm{C}^{\circ}$ ) (Bruniard 1999). Las lluvias son abundantes, frecuentes e irregulares a lo largo de todo el año, con alta concentración en verano-otoño (Bruniard 1999; Carnevali 1994).

Debido a las características topográficas y paleohidrológicas (cambios de cursos de grandes ríos) de la región se ha formado una serie de sistemas de humedales (lagunas y esteros), destacándose especialmente el extenso sistema del Iberá y otros 
similares de menor envergadura. Hacia el noreste de la provincia prevalecen los malezales de los ríos Aguapey y Miriñay, que se extienden desde los limites del sistema Iberá hacia la provincia de Misiones y el río Uruguay. La mayoria de los humedales de esta región están relacionados al río Paraná, y sus paleocauces, y en menor escala al río Uruguay, ambos correspondientes a la cuenca del río de la Plata (Canevari et al. 1998).

Desde el punto de vista de su vegetación, confluyen en Corrientes dos Dominios fitogegráficos (Cabrera 1976): Dominio Chaqueño, que cubre la mayor parte de su superficie, conformado por la Provincia Chaqueña con el Distrito el Chaqueño Oriental, y la Provincia del Espinal con el Distrito del Ñandubay; y Dominio Amazónico, en el ángulo noreste de Corrientes, representado por la Provincia Paranaense y el Distrito de los Campos. El centro y sur de la provincia está caracterizado por sabanas-parque, un mosaico de bosques xerófilos caducifolios con estepas herbáceas y arbustivas donde predomina el espinillo o ñandubay, tanto en las sabanas como en las formaciones boscosas. Por el nordeste de Corrientes, limitado por el río Paraná al norte, por el río Uruguay y la provincia de Misiones al noreste y por los esteros del Iberá y el curso inferior del río Aguapey al oeste; dominan las sabanas de gramineas de hasta un metro y medio de altura, con formaciones selváticas en los márgenes de ríos y lagunas o formando pequeñas isletas. La mayor parte está ocupada por las sabanas secas y pastizales secos a húmedos con isletas de bosque hidrófilos (Carnevali 1994). En los valles aluviales del Uruguay y sus afluentes predominan bosques subtropicales y un complejo de vegetación palustre y acuática con malezales y pastizales húmedos.

Otra clasificación ecorregional es la propuesta por Burkart et al. (1999), quienes describen para Corrientes cinco eco- rregiones: Chaco Húmedo, Delta e Islas del Paraná, Esteros del Iberá, Campos y Malezales y Espinal. Las ecorregiones Chaco Húmedo y Espinal son coincidentes con las características brindadas para las provincias fitogeográficas homónimas, mientras que la eco-región Campos y Malezales, concuerda con el Distrito de los Campos de la provincia fitogeográfica Paranaense.

Estos espacios diversos resultaron atractivos para la ocupación humana, que data desde aproximadamente 11.000 años AP (Ceruti 2000). Las diferentes sociedades -primero cazadoras recolectoras, luego horticultoras y pescadoras- progresivamente los fueron ocupando y aprovechando la disponibilidad de recursos a través del tiempo. Lamentablemente en la actualidad se observa una creciente pérdida en los ambientes acuáticos debida, principalmente, a la degradación ambiental, la contaminación y la creciente apropiación del agua para diferentes usos humanos en toda la región (Canevari et al. 1998). El aumento de la población humana, con el creciente desarrollo de la economía y el desarrollo de la infraestructura, deforestación, erosión, contaminación de las aguas, la utilización de las tierras para diferentes usos (agrícola, ganadero, forestal y/o urbano), introducción de especies exóticas, entre muchos otros factores, provocan el deterioro o pérdida de estos ambientes (Benzaquén et al. 2013), junto con la pérdida del registro arqueológico y patrimonial correspondiente.

\section{Marco teórico metodológico}

El paisaje puede ser considerado un entorno físico y perceptivo creado en un proceso de apropiación del medio por las sociedades humanas que lo habitan, es una construcción social (Criado Boado 1993) que conserva en su materialidad las marcas de la acción humana (Vicent 
García 1998). Los paisajes monumentales son aquellos que presentan características de visibilización/monumentalidad (Villoch 1998). Se entiende a la Monumentalización como la acción de construcción colectiva social, en vinculación con determinados rasgos del paisaje, sean accidentes geográficos o evidencias culturales, que adquieren un valor particular compartido, dadas sus características intrinsecas, los cuales son apropiados por las poblaciones locales, situación que en algunos casos se mantiene durante tiempos prolongados (Oliva et al. 2013). Un monumento constituye un producto intencional que enraíza en el presente la memoria (histórica) de un grupo (Gil García 2003), y queda emplazado en un espacio concreto, elegido concienzudamente para la ocasión, con el propósito de que la ostentación visual contribuya a ese continuo feedback del pasado en el presente.

Criado Boado (1993:46) indica que todo monumento es "un agregado de resultados intencionales concretados en un producto artificial visible en términos espaciales y que mantiene esta visibilidad a lo largo del tiempo". En esta perspectiva, la visibilidad es considerada como "la forma de exhibir y destacar los productos de la cultura material que reflejan la existencia de un grupo social. Dado que los efectos se reflejan espacialmente, podemos definir las condiciones de visibilidad del registro arqueológico extendiendo una 'mirada' sobre los elementos que lo componen que intenta determinar el qué, cómo y por qué de sus rasgos visuales" (Criado Boado1991:23). Las estrategias de visibilidad implicadas en el proceso de monumentalización, representan "situaciones en las que se introduce una paulatina y, a menudo, inconsciente ruptura con el orden salvaje" (Criado Boado 1993:50-51). Los monumentos son lugares con un fuerte contenido ideológico, simbólico y social que se manifiestan en el espacio y a través del tiempo (Bradley
1993:5).

La domesticación del espacio natural por parte de las sociedades cazadoras recolectoras puede ser lograda a través de monumentos generadores de un nuevo tipo de paisaje, y del control del tiempo obtenido por la visibilidad y permanencia de la acción social, expresada en registros inmuebles (Vicent García 1991). Deben destacarse en este marco teórico, los conceptos de visibilidad, vinculado a la capacidad de ser visible desde fuera; y visibilización, relacionado a la capacidad de proporcionar visión desde adentro hacia afuera (Criado Boado 1999).

La información geográfica fue volcada en un Sistema de Información Geográfica (SIG) como herramienta para el análisis espacial en general, y la construcción de cuencas visuales como caso particular, entendida como el conjunto de superficies o zonas que son vistas desde un punto de observación (Fernández-Cañadas 1977; Wheatley y Gillings 2002). El área buffer de estudio está comprendida por un radio de $30 \mathrm{~km}$ de visibilidad, lo cual nos da una superficie de $2.800 \mathrm{~km}^{2}$ aproximadamente. Se construyó un modelo para el cálculo de las cuencas visuales cuyos datos de entrada son el Modelo de Elevación (MED). Paralelamente, con la información de base procedente de las curvas de nivel se lleva a cabo un proceso de interpolación espacial para generar el Modelo Digital de elevaciones en formato raster, imprescindible para definir la cuenca visual a partir de la cual obtener gran cantidad de información sobre la morfología del territorio circundante al punto elegido de búsqueda. Los mapas raster derivados permiten analizar el comportamiento de las variables sobre el territorio.

La cuenca visual es el conjunto de superficies o zonas que son vistas desde un punto de observación (Fernández Cañadas 1977). La cuenca visual común de los puntos que pertenecen a una zona es la 
intersección del conjunto de las cuencas visuales correspondientes a dichos puntos. La cuenca visual conjunta de los puntos que pertenecen a una zona es la unión del conjunto de cuencas visuales de cada uno de ellos. Una definición más específica de cuenca visual es aportada por García Sanjuán et al. (2006), como el conjunto de todas las localizaciones o puntos de un territorio que son visibles desde un punto de observación específico, dada una distancia máxima de visión, y en base únicamente a la topografia.

El procedimiento más ajustado para determinar con mayor precisión la cuenca visual se basa en el uso de un Modelo Digital del Terreno (MDT o DTM, Digital Terrain Model), y su correspondiente cálculo automático. El terreno en la realidad es una superficie continua que, a la hora de su tratamiento en forma numérica, hay que convertirla en una superficie poliédrica. Para ello, al terreno se le superpone una red o malla que puede estar compuesta por cuadrados, triángulos, o hexágonos y se registran las cotas de sus vértices (Oliva et al. 2013). El caso más corriente es utilizar superficies cuadrangulares, a las que suele darse la denominación de cuadrículas, celdas o teselas.

El análisis de cuencas visuales se realiza usando como datos de entrada al modelo de elevación digital en formato raster y un dato puntual en un archivo vectorial de puntos que indica la localización de interés (el punto de observación). La aplicación del algoritmo permite definir la cuenca visual, es decir, considerando la forma del terreno, determina cuales celdas son visibles e invisibles desde ese punto de observación. El resultado es un mapa binario cuyas celdas con valor 1 son "visibles" y las de valor 0 "invisibles". E1 total de celdas visibles constituye su "cuenca visual" (Wheatley y Gillings 2002). Las cuencas visuales amplias definen una vista panorámica desde el punto de observación. Por el contrario, cuencas visuales estrechas están formadas por pocas celdas, ya que representan un área visible menor.

Dentro de la óptica, se considera que el campo visual es el área dentro del cual se perciben imágenes alrededor de un objeto determinado sobre el cual se mantiene la vista fija, variando de persona a persona dentro de un cierto intervalo. El ojo humano dispone de un campo visual de aproximadamente $150^{\circ}$, y con la superposición de ambos, alcanza una amplitud de $180^{\circ}$ sobre el plano horizontal. Sobre el plano vertical es de $130^{\circ}, 60^{\circ}$ por encima y $70^{\circ}$ por debajo del ojo. Estos límites coinciden con los del mismo lado del campo binocular, aproximadamente $91,5^{\circ}$ y en porción primaria de la mirada abarcan $64^{\circ}$ en dirección nasal, $55^{\circ}$ en el sentido superior y $75^{\circ}$ en el inferior (Jay 1981).

La voluntad de visibilidad varía según el tipo de sociedad, y por lo tanto, la forma de representar la cultura material y las estrategias de hacerla visible cambian en función del patrón de racionalidad de estas sociedades (Irujo Ruiz y Prieto Martínez 2005). Las propiedades visuales de una localización pueden ser importantes factores en las decisiones de asentamiento. Si bien los motivos pueden ser principalmente funcionales, una buena vista del entorno puede influir en la elección de un emplazamiento.La visibilidad es una medida de la capacidad del lugar para proporcionar a un observador visión sobre el entorno circundante. El solapamiento de áreas de visibilidad desde dos o más sitios se denomina intervisibilidad, y a través de ella se puede suponer una relación entre los lugares que están conectados visualmente.

\section{Los sitios analizados}

Itá Pucú se encuentra ubicada próxima a la localidad de Mercedes, donde las creencias populares postulan que esta pie- 

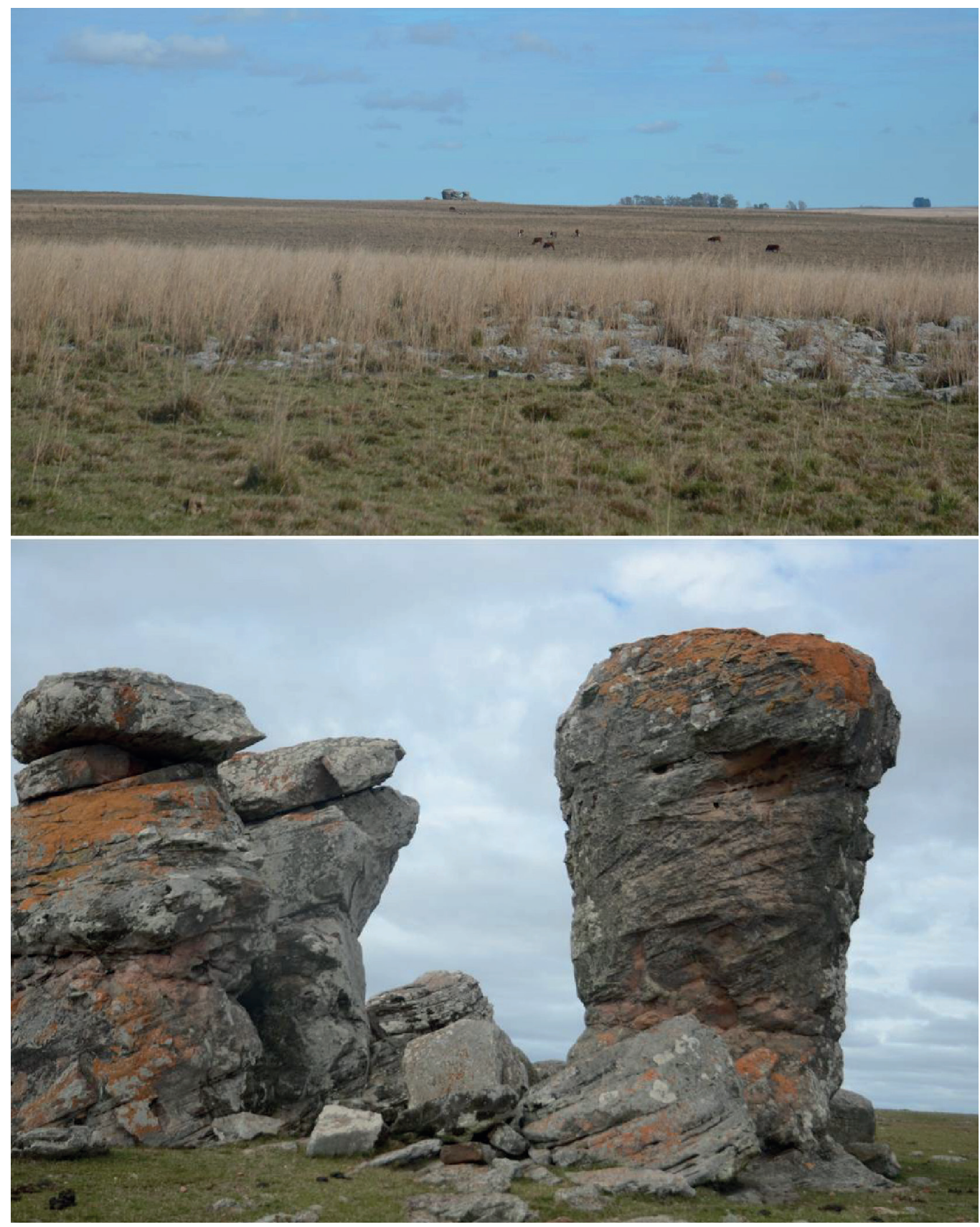

Figura 2. Arriba una foto del ambiente de llanura donde sobresale la formación geológica conocida como Itá Pucú. Abajo se observa un primer plano del monumento natural. 
dra crece (Figura 2). Entre otros, Bonpland después de observar la ladera de las rocas, su composición y la presencia de liquen que indica su antigüedad, consigna el testimonio de un hombre que afirma haber visto a aumentar el volumen de la piedra. Demersay (1860-1865) asiste a Bonpland en sus contribuciones en esta área y describe la "roca de la Asunción" o la de la Itá Pucú como bloques de piedra arenisca aislados en un pequeño espacio en el centro de las planicies. Traduce Ita-pucu como Piedra-larga. Describe que la piedra larga se encuentra en el noreste y las rocas que dependen de él, al sudoeste; la arenisca es de color blanco grisáceo arenisca y grano fino. Las rocas están cubiertas de líquenes. El sitio es erosionado por la acción combinada del agua, el sol y los vientos.

Este monumento natural habría sido significativo como hito en el espacio para las poblaciones prehispánicas, y por la amplia visibilidad circundante que ofrece; para las poblaciones históricas habria continuado manteniendo este valor, ya que habria sido visitado por varias personalidades que dejaron grabados sus nombres sobre el substrato rocoso (graffiti históricos), entre los cuales pueden mencionarse José María Paz y Bartolomé Mitre.

Los relatos orales recopilados en el lugar refieren que la población nativa que vivió en sus alrededores le atribuía poderes a esta roca (Itá Pucú) cuando expresaban que la misma crece; asimismo los antiguos pastores de ganado que debieron permanecer por su trabajo en el lugar dijeron que han escuchado que la roca "habla" y que se oyen en el lugar ruidos raros, por eso manifiestan que hay un "pora" (término guaraní que significa poder o fuerza, es análogo al maná) poderoso que es propio del lugar.

Los pobladores locales refieren que en épocas pasadas el campo fue remonta de caballería y por eso era visitada por muchos viajeros que dejaron allí sus nombres como José María Paz en 1841 cuando formó el ejército Libertador de Corrientes, Giuseppe Garibaldi en la época que fue vencido en Costa Brava y se internó en Mercedes; Bartolomé Mitre cuando retornó de los campos del Paraguay para hacerse cargo nuevamente de la Presidencia de la Nación; y que el General Osorio acampó en ese lugar por el año 1865 siguiendo su marcha hacia el oeste de Mercedes.

El Paraje Tres Cerros, próximo a la localidad de La Cruz, se encuentra ubicada en el centro este de la provincia de Corrientes (Figura 3). Presenta un relieve topográfico de afloramientos rocosos constituidos por areniscas cuarzosas del periodo Jurásico Superior - Cretácico Inferior (Herbest y Santa Cruz 1999) correspondientes a la formación estratigráfica Botucatú (Aceñolaza 2007). Este afloramiento abarca tres cerros, que se destacan en la llanura correntina como "islas" rocosas, denominados Nazareno (179 msnm), Chico (148 msnm) y Capará (158 msnm); la zona occidental del cerro Nazareno puede ser considerada como un cuarto cerro, El Pelón (131 msnm). Los cerros se caracterizan por una geomorfologia de dunas con cumbres truncadas que forman una divisoria topográfica de orientación Sudeste-Noroeste (Aceñolaza 2007). Desde el punto de vista fitogeográfico los cerros se localizan en el distrito de los Campos de la provincia Paranaense (Cabrera y Willink 1980); entre las cumbres, la ladera norte presenta vegetación arbustiva rala y gramíneas y la ladera sur un bosque higrófilo primario constituido por elementos florísticos de la selva paranaense misionera (Parodi 1943).

Los sitios arqueológicos emplazados en este paraje corresponden a corrales jesuíticos confeccionados en piedra registrados en el cerro El Nazareno, los que podrian haber estado vinculados con la utilización jesuita del territorio. El Paraje Tres Cerros era un lugar prácticamente desconocido para la ciencia hasta hace unos años, pese 


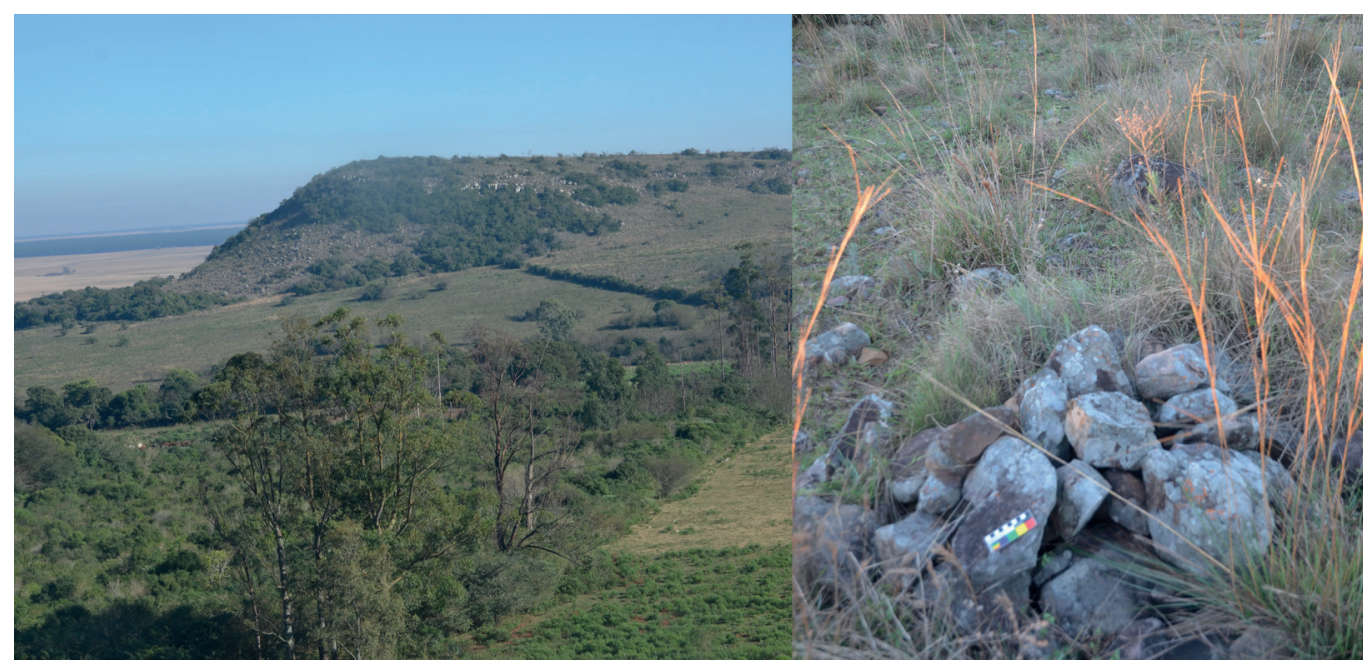

Figura 3. Izquierda: vista del paraje Tres Cerros. Derecha: detalle de los restos de un corral de piedras relevado en Tres Cerros.

a que en el año en el año 1885 el reconocido naturalista Amado Bonpland destacaba la necesidad de conocer y estudiar este paisaje único por su biodiversidad. Este ecosistema alberga unas 350 especies de plantas vasculares, 40 de peces, 52 de herpetozoos, 200 de aves, 40 de mamíferos y una amplia variedad de invertebrados. Esta biodiversidad incluye aves migratorias que tienen a los cerros como destino en primavera y verano, especies con poblaciones naturales relictuales o amenazadas de extinción. La característica fundamental y distintiva del ecosistema son las especies endémicas, que sólo habitan en los afloramientos del Paraje Tres Cerros y en ningún otro lugar del mundo: el cactus globular Gymnocalycium angelae, el lirio del cerro Amaryllis euryphylla y un lirio amarillo Cypella trimontina, las lagartijas Homonota taragui o geko del taragüi y Cnemidophorus sp. o lagartija de Bonpland y un escorpión (Tityussp.).

También el lugar ha resultado atractivo para la realización de diferentes propuestas deportivo-recreativas, como La Cruz
TrailRun "Espíritu Mbororé", eventos en el marco de los cuales el ambiente puede verse afectado por las actividades humanas. Por este motivo, la "Reserva Natural Privada Paraje Tres Cerros" fue creada por convenio establecido entre la empresa Forestadora S.A. y la Fundación Amado Bonpland, que tiene a su cargo la ejecución de un plan de gestión integral. La Reserva protege un área en la que se ubican dos de los tres cerros: "Nazareno" de una altura de 179 metros sobre el nivel del mar (msnm) y el cerro "Chico" de 148 metros msnm. En la nueva área protegida se establecieron medidas básicas de conservación de la naturaleza, se diseñó cartelería informativa y se trazaron senderos que podrán ser recorridos por los visitantes acompañados por guías de naturaleza especialmente capacitados para mostrar y explicar las características del lugar. En este plan de manejo participan los equipos de investigación en biología encabezados por Alejandra Hernando y Rodrigo Cajade, de la Universidad Nacional del Nordeste. 


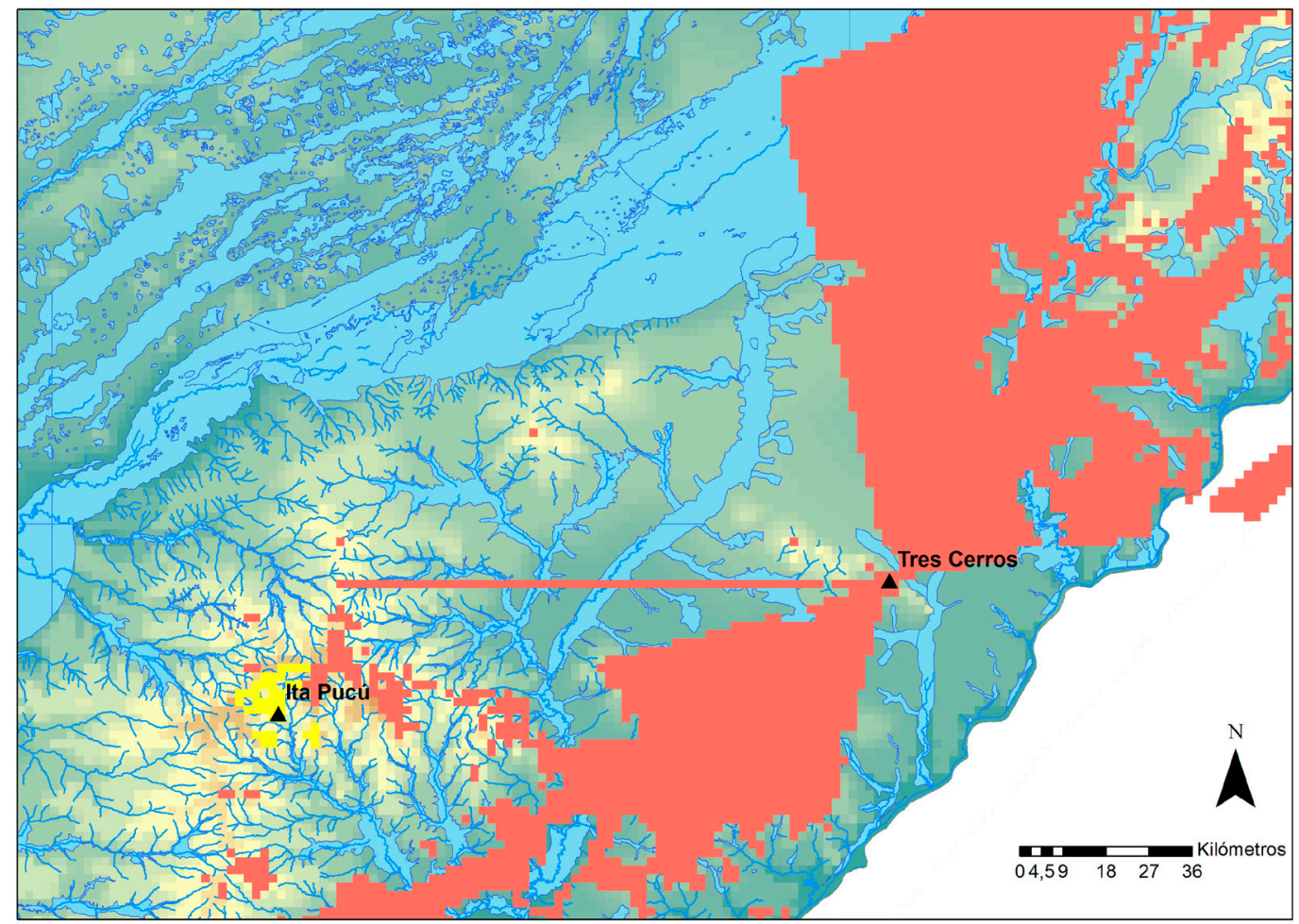

Figura 4. Análisis de las cuencas visuales, en color rojo la correspondiente a Tres Cerros, en amarillo la cuenca vinculada con Itá Pucú.

\section{Resultados}

En los sitios mencionados previamente se evaluaron distintos indicadores de monumentalidad (cuencas visuales, punto del observador, visibilidad del sitio, entre otros). Los dos sitios obtuvieron valores diferenciales en estas pruebas (Figuras 4 y 5). En este sentido, Itá Pucú presentó valores menores y Tres Cerros valores mucho mayores, estos resultados podrian vincularse con la mayor altura de este último paraje, pero se considera que ambos podrian estar representando una estrategia de visibilización que los convertiría en ejemplos de monumentos salvajes (Criado Boado 1993), por constituir elementos naturales con características sobresalientes para su percepción con respecto al entorno. Dentro del área son lugares que se destacarian por una continuidad en la ocupación prehispánica - jesuita. En un paisaje uniformemente llano, estos sitios sobresalen con una altura relativa que les aseguraría el control visual del entorno y su visibilidad a grandes distancias.

El sector centro-oriental de la provincia de Corrientes se encuentra fuertemente modificado como efecto de la actividad agrícola-ganadera y de la introducción de exóticas vegetales y animales que han transformado el paisaje original. El estado de deterioro que presentan se corresponde con la alteración esperable por factores 


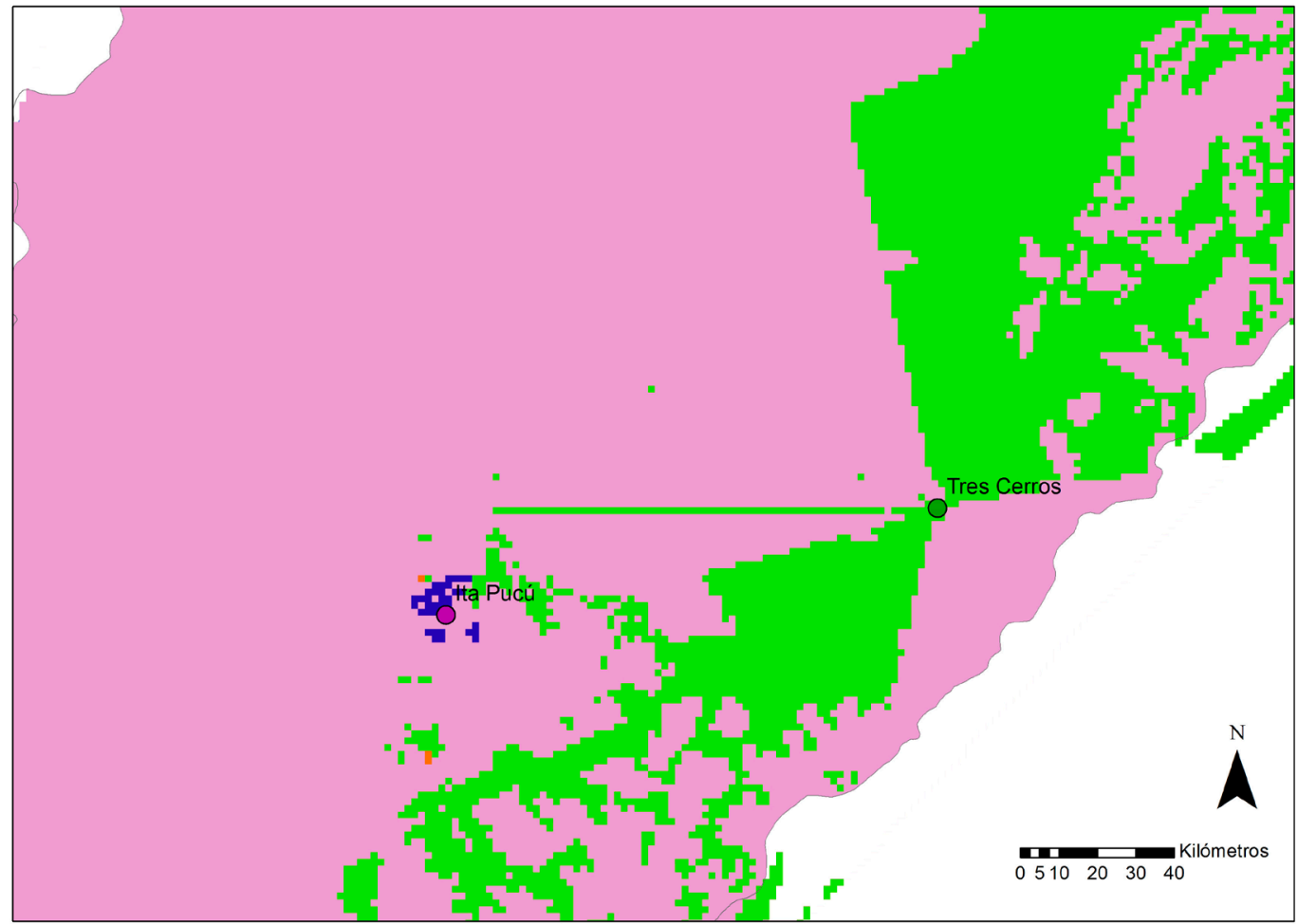

Figura 5. Prueba del punto del observador, en rosa el terreno no visible desde ambos puntos, en verde el área visible desde Tres Cerros, en violeta, la zona visible desde Itá Pucú.

ambientales (erosión hídrica, eólica y solar) y biológicos (crecimiento de musgos y líquenes), agravado por los efectos del turismo no regulado. A través del tiempo, las sociedades que habitaron estos espacios les habrian otorgado una serie de significaciones y construido un conjunto de relatos vinculados a su carácter inmueble, visible y perdurable.

\section{Consideraciones finales}

En el marco de la arqueología del paisaje, se propone que los sitios estudiados podrian haber funcionado como "hitos", como referentes espaciales para conseguir orientación en el paisaje, como indicadores de caminos y límites o fronteras entre grupos. La ubicación de los sitios y localidades arqueológicas puede estar determinada por la asociación con rasgos geográficos específicos tales como accidentes topográficos, cerros, canteras y cursos de agua (Whitley y Loendorf 2005), aspectos topográficos del paisaje que juegan un papel central. Este entorno es el resultado de los procesos cíclicos y lineales, tanto como de las propiedades estructurales de los sitios, en función de la interrelación entre las sociedades pasadas y actuales, y de los agentes que intervinieron en ellas, que determinan la visibilidad paisajística de los sitios. 
La domesticación del espacio natural por parte de las sociedades cazadoras recolectoras primero, y sedentarias con sistemas de producción de alimentos después, puede ser lograda a través de monumentos generadores de un nuevo tipo de paisaje, y del control del tiempo obtenido por la visibilidad y permanencia de la acción social, expresada en registros inmuebles; en este sentido el espacio particular donde se emplazan las evidencias se constituye en una huella de la construcción social del paisaje. Ambos lugares constituirian ejemplos de monumento salvaje en el sentido de Criado Boado (1993:48), un elemento natural de características destacables, que es percibido y aislado del resto de los elementos del paisaje; que posteriormente se podrian haber transformado en monumentos ambiguos (Criado Boado 1993:48).

Las propiedades visuales de una localización, como la amplia visibilidad del entorno, como es el caso de Itá Pucú, pueden ser importantes factores en la elección de un emplazamiento. En este sentido, el concepto de control visual de un espacio puede aportar elementos para discutir la hipótesis que postula a los sitios vinculados al manejo y control territorial del nacimiento de las cuencas hídricas con los sitios localizados en puntos estratégicos con amplia visibilidad.

En el caso del actual territorio de la provincia de Corrientes, se observa una lógica de asentamiento vinculada con el control hídrico del espacio más generalizada para los grupos prehispánicos y con un control visual relacionado con los puntos más elevados sobre el terreno; y por otro lado una lógica post-hispánica que selecciona los principales cursos de agua para establecerse (Paraná y Uruguay), con una concentración mucho mayor sobre el río Uruguay. En este panorama, pueden estar interviniendo: 1. la diferencia en el lapso temporal abarcado por ambas sociedades, 2. el tipo de características culturales de- sarrolladas, o en el peor de los casos, 3. el sesgo de investigación de los estudios precedentes.

\section{Agradecimientos}

A Alejandra Hernando, Rodrigo Cajade, Humberto Micheli, Ana Ferrando, Dardo Montiel, la Municipalidad de Mercedes y los propietarios de la Reserva Natural Privada Tres Cerros. Al evaluador, quien enriqueció el trabajo con sus sugerencias y observaciones. Las tareas se enmarcan en el Proyecto HUM 557 Expresiones gráficas y arqueología monumental en el sector centro oriental de la provincia de Corrientes acreditado en la Universidad Nacional de Rosario.

\section{Bibliografia}

ACEÑOLAZA, F.G. 2007. Geología y recursos geológicos de la Mesopotamia Argentina. Instituto Superior de Correlación Geológica (INSUGEO), Serie Correlación Geológica 22, INSUGEO, Tucumán.

ACOSTA, F.; L. GIMENEZ; C. RICHIERI y M. CALVI. 2009. Zonas Agro-Económicas Homogéneas. Corrientes. Descripción ambiental, socioeconómica y productiva. En Estudios socioeconómicos de la sustentabilidad de los sistemas de producción y recursos naturales INTA Corrientes $\mathrm{N}^{\circ}$ 8, Corrientes. pp. 1-75.

BENZAQUÉN, L.; D. BLANCO; R. BÓ; P. KANDUS; G. LINGUA; P. MINOTTI; R. QUINTANA; S. SVERLIJ y L. VIDAL (eds.). 2013. Inventario de los Humedales de Argentina. Sistemas de paisajes de humedales del Corredor Fluvial Paraná-Paraguay. Secretaría de Ambiente y Desarrollo Sustentable de la Nación, Buenos Aires.

BRADLEY, R. 1993. Altering the Earth: The Origins of Monuments in Britain and Continental Europe. Monograph Series 8, Society of Antiquaries of Scotland, Edinburgh. 
BRUNIARD, E. 1999. Los regímenes hídricos de las formaciones vegetales. EUDENE-UNNE, Corrientes.

BURKART, R.; N. BÁRBARO; R.O. SÁNCHEZ y D.A. GÓMEZ. 1999. Eco-regiones de la Argentina. Programa Desarrollo Institucional Ambiental Administración de Parques Nacionales, Secretaria de Recursos Naturales y Desarrollo Sustentable, Buenos Aires.

CABRERA, A.L. 1976. Regiones fitogeográficas argentinas. En Enciclopedia Argentina de Agricultura y Jardinería, Volumen II, editado por W.F. Kugler. ACME, Buenos Aires.

CABRERA, A.L. y A. WILLINK. 1980. Biogeografía de América Latina. Monografia 13, Organización de los Estados Americanos, Washington, D.C.

CANEVARI, P.; D. BLANCO; E. BUCHER; G. CASTRO y I. DAVIDSON. 1998. Los humedales de la Argentina. Clasificación, situación actual, conservación y legislación. Publication 46. Wetlands International, Buenos Aires.

CARNEVALI, R. 1994. Fitogeografia de la Provincia de Corrientes. Gobierno de la Provincia de Corrientes e Instituto Nacional de Tecnología Agropecuaria (INTA), Litocolor, Asunción.

CERUTI, C. N. 2000. Ríos y praderas: los pueblos del Litoral. En Nueva historia argentina. Los pueblos originarios y la conquista, editado por M. Tarragó, pp. 105-146. Sudamericana, Buenos Aires.

CRIADO BOADO, F. 1993. Visibilidad e interpretación del registro arqueológico. Trabajos de Prehistoria 50:39-56.

CRIADO BOADO, F. 1999. Del Terreno al Espacio: Planteamientos y Perspectivas para la Arqueología del Paisaje. Capa 6:1-82.

DEMERSAY, A. 1860-1865. Histoire physique, économique et politique du Paraguay et des établissements des jésuites. Hachette, Paris.

ESCOBAR, E.H. 1982.Suelos afectados por anegamiento en la provincia de Corrientes. EEA INTA, Corrientes.

FERNÁNDEZ CAÑADAS, M. 1977. El paisaje en la planificación física. Aproximación sistemática a su valoración. Tesis doctoral. E.T.S.I. de Montes, Madrid.

GARCÍA SANJUÁN, L.; S. METCALFE-WOOD; T. RIVERA JIMÉNEZ y D. WHEATLEY. 2006. Análisis de pautas de visibilidad en la distribución de monumentos megalíticos de Sierra Morena Occidental. En La aplicación de los SIG en la arqueología del paisaje, editado por I. Grau Mira, pp. 181-200. Publicaciones de la Universidad de Alicante, Alicante, España.

GIL GARCÍA, F.M. 2003. Manejos espaciales, construcción de paisajes y legitimación territorial: en torno al concepto de monumento. Complutum 14:19-38.

HERBST, R. y J.N. SANTA CRUZ. 1999. Mapa litoestragráfico de la provincia de Corrientes. D'Orbigniana 2:1-69.

IRUJO RUIZ, D.J. y M.P. PRIETO MARTINEZ. 2005. Aplicaciones del 3D en cerámica prehistórica de contextos arqueológicos gallegos: Un estudio sobre percepción visual. ArqueoWeb: Revista sobre Arqueología en Internet (Universidad Complutense de Madrid) 7(2). https://webs.ucm.es/info/arqueoweb/ pdf/7-2/irujoruiz

JAY, W.M. 1981. Visual field defects. American Family Physician 24(2):138-142.

OLIVA, F.; M.C. PANIZZA y R. RUIZ. 2013. Cuencas visuales vinculadas con el estudio del paisaje y del arte rupestre en el Sistema Serrano de Ventania. En Arqueometría argentina: estudios pluridisciplinarios, editado por M. Ramos, M. Lanza, V. Helfer, V. Pernicone, F. Bognanni, C. Landa, V. Aldazabal, y M. Fernández, pp. 99-111. Aspha Ediciones y Programa de Arqueología Histórica y Estudios Pluridisciplinarios, Departamento de Ciencias Sociales, Universidad Nacional de Luján, Luján. 
PARODI, L.R. 1943. La vegetación del departamento San Martín en Corrientes, Argentina. Darwiniana 6:127-178.

VICENT GARCIA, J.M. 1991. Fundamentos teórico-metodológicos para un programa de investigación arqueo-geográfica. En El cambio cultural del IV al II milenios a. de C. en la Comarca Noroeste de Murcia. Volumen I, editado por P. López, pp. 31-117. CSIC, Documentación, Madrid.

VICENT GARCÍA, J.M. 1998. Entornos. Arqueologia Espacial 19-20:165-168.

VILLOCH, V. 1998. Paisajes monumentales en un mismo espacio: la sierra de O Bocelo (Galicia). Arqueología Espacial 19-20:517-528.

WHEATLEY, D. y M. GILLINGS. 2002.Spatial technology and archaeology: the archaeological applications of GIS. Taylor \& Francis, Londres.

WHITLEY, D. y L. LOENDORF. 2005. Rock art analysis. En Handbook for Archaeological Methods II, editado por H. Maschner y C. Chippindale, pp. 919-976. Altamira Press, New York. 